\title{
EFEITO DA TEMPERATURA DE ENCHARQUE E DO RESFRIAMENTO CRIOGÊNICO NO TRATAMENTO TÉRMICO DE LIGA DE Fe-Ni-Cr *
}

\author{
Larissa Fernandes Nunes ${ }^{1}$ \\ Noan Tonini Simonassi2 \\ Andersan Dos Santos Paula
}

\begin{abstract}
Resumo
O presente trabalho teve como objetivo caracterizar a temperabilidade de uma liga $\mathrm{Fe}-\mathrm{Ni}-\mathrm{Cr}$. Amostras do material foram submetidas a temperaturas de encharque de $800^{\circ} \mathrm{C}$ e $1100^{\circ} \mathrm{C}$ e resfriadas utilizando salmoura e nitrogênio líquido. Para a caracterização do material, foram realizadas análises de EDS, MEV e DRX para se determinar, respectivamente, a composição química das fases, a microestrutura e a transformação de fases que podem ter ocorrido. Os resultados microestruturais não mostraram evidencias de transformação de fase, mas que houve o surgimento de maclas de deformação associadas à ciclagem térmica. No entanto a difração de raios- $x$ para amostras tratadas a $800^{\circ} \mathrm{C}$, com aparentemente segregação intergranular, evidenciou alguma transformação de fase.

Palavras-chave: Liga Fe-Ni-Cr; Temperatura de encharque; Resfriamento Criogênico; Microestrutura.

\section{EFFECT OF SOAKING TEMPERATURE AND CRYOGENIC COOLING ON Fe-Ni-Cr ALLOY HEAT TREATMENT}

\section{Abstract}

The present work had the objective to characterize the temperability of a $\mathrm{Fe}-\mathrm{Ni}-\mathrm{Cr}$ alloy. The samples were submitted of soaking temperatures $800^{\circ} \mathrm{C}$ and $1100^{\circ} \mathrm{C}$ and the cooling fluids used were brine and liquid nitrogen. For the characterization of the material, analyzes of EDS, SEM and XRD were conducted to determine the chemical composition, the microstructure and the phase transformation that can be occurred. The microstructural results don't showed evidences of phase transformation, but a formation of deformation twins associated with thermal cycling. However, the XRD for $800^{\circ} \mathrm{C}$ heat treated samples, with apparently intergranular segregation, shown some phase transformation occurred.

Keywords: Fe-Ni-Cr Alloy; Soaking temperature; Cryogenic Cooling; Microstructure.

1 Engenheira Metalurgista, Mestranda em Ciência dos Materiais do Programa de Pós-graduação em Ciência dos Materiais, Seção de Engenharia Mecânica e de Materiais - SE/4, Instituto Militar de Engenharia - IME, Rio de Janeiro, RJ, Brasil.

2 Engenheiro Metalurgista, Mestre em Ciência dos Materiais, Doutorando em Ciência dos Materiais do Programa de Pós-graduação em Ciência dos materiais, Instituto Militar de Engenharia - IME, Rio de Janeiro, RJ, Brasil.

3 Engenheira Metalurgista, Mestre e Doutora em Ciência dos Materiais, Professora Adjunta do Programa de Pós-graduação em Ciência dos Materiais e Graduação, Seção de Engenharia Mecânica e de Materiais - SE/4, Instituto Militar de Engenharia - IME, Rio de Janeiro, RJ, Brasil 


\section{INTRODUÇÃO}

A adição de elementos de liga nos aços permite a obtenção de uma vasta possibilidade de combinações entre resistência mecânica e composição química. Elementos tais como o níquel e manganês, por exemplo, aumentam a estabilidade da austenita permitindo que a mesma esteja estável mesmo a temperatura ambiente. $\mathrm{O}$ acréscimo de elementos tais como cromo e titânio, isolados, provocará uma elevação da estabilidade da ferrita, através da inibição da austenita. Entretanto, quando ocorre a adição de cromo juntamente com o níquel em quantidades mínimas, este irá ocasionar o retardo da cinética de transformação da austenita para a ferrita, favorecendo o aparecimento da austenita retida a temperatura ambiente [1]. Superligas à base de níquel e os aços inoxidáveis austeníticos são os principais representantes das ligas $\mathrm{Fe}-\mathrm{Cr}-\mathrm{Ni}$. Os aços inoxidáveis austeníticos apresentam excelente resistência à corrosão e à oxidação devido à formação de uma fina camada superficial de óxido denso e aderente, porém, suas características de desgaste e de dureza são relativamente baixas. Enquanto as superligas a base de níquel possuem adições de outros elementos para a obtenção de resistência mecânica satisfatória a temperaturas elevadas [2,3].

Os aços inoxidáveis austeníticos são ligas $\mathrm{Fe}-\mathrm{Cr}-\mathrm{Ni}$, contendo geralmente de 16\% até $26 \%$ de cromo e de $6 \%$ de $22 \%$ de níquel. Esses aços são designados pelas séries 300 e 200, segundo o método de classificação da American Iron and Steel Institute (AISI). Devido á esta estrutura austenítica, essa classe apresenta estrutura cúbica de face centrada (CFC), possui características não magnéticas e podem ser endurecidos por trabalho a frio. O endurecimento por deformação a frio pode elevar o limite de resistência e escoamento acima de $1000 \mathrm{MPa}$ apresentando alongamento na faixa de 10 a $15 \%[4,5,6]$.

Os aços inoxidáveis austeníticos da classe ABNT 310 possuem cerca de $25 \% \mathrm{Cr}$ e $20 \% \mathrm{Ni}$. Essa liga é conhecida por seu comportamento em resistência à corrosão em elevadas temperaturas. No estado recozido eles apresentam limite de escoamento de aproximadamente $240 \mathrm{MPa}$ e resistência de $540 \mathrm{Mpa}[7,8]$

Em alguns dos aços inoxidáveis austeníticos, a martensita pode ser induzida termicamente durante o resfriamento em temperaturas abaixo da temperatura ambiente, ou mecanicamente por trabalho a frio. As equações 1 [6] e 2 [9] representam métodos empíricos para calcular a temperatura de início da transformação martensítica em função dos elementos de liga.

$$
\begin{aligned}
& \mathrm{M}_{\mathrm{s}}=75(14,6-\% \mathrm{Cr})+110(8,9-\% \mathrm{Ni})+60(1,33-\% \mathrm{Mn})+50(0,047- \\
& \% \mathrm{Si})+3000[0,068-(\% \mathrm{C}+\% \mathrm{~N})] \\
& M_{s}=1350-1665(\mathrm{C}+\mathrm{N})-28(\mathrm{Si})-33(\mathrm{Mn})-42(\mathrm{Cr})-61(\mathrm{Ni})
\end{aligned}
$$

Através dessas equações é possível observar que o carbono e nitrogênio apresentam efeito muito elevado, enquanto que o cromo e níquel têm um efeito moderado em relação ao decrescimento de $\mathrm{M}_{\mathrm{s}}$ [6].

Esses aços inoxidáveis podem apresentar duas fases martensíticas que são $\varepsilon$ (HC hexagonal compacta) e $\alpha^{\prime}$ (CCC - cúbica de corpo centrado). A quantidade e o tipo de fase que aparecem nesses aços dependem da temperatura, da falha de empilhamento e da quantidade de deformação, fatores que são fortemente influenciados pela composição química da liga [10].

Materiais que apresentam estrutura cristalina CFC possuem uma falha de empilhamento em particular. Elas são uma das mais importantes imperfeições 
introduzidas pela movimentação que se dissociam e tornam-se discordâncias parciais, com capacidade ou não de se recombinar em função do valor da EFE. Apresentam um papel importante no processo de deformação plástica, pois controlam a capacidade de encruamento, a corrosão sob tensão, e a capacidade de estiramento e o tipo e quantidade de martensita formada [11].

A energia de falha de empilhamento é um parâmetro dependente da composição química e desempenha um papel fundamental para a estabilização da austenita [12]. Ela pode ser estimada por equações empíricas em função dos elementos de liga presentes no aço. Entretanto estas equações são limitadas a alguns sistemas de liga, não sendo aplicadas para todos os aços inoxidáveis austeníticos. As equações 3 [13] e 4 [14] são equações muito utilizadas para se estimar o valor da energia de falha de empilhamento dos aços inoxidáveis do sistema Fe-Cr-Ni.

$$
\begin{aligned}
& \operatorname{EFE}\left(\mathrm{mJ} / \mathrm{m}^{2}\right)=-53+0,7(\% \mathrm{Cr})-6,2(\% \mathrm{Ni})-3,2(\% \mathrm{Mn})+9,3(\% \mathrm{Mo}) \\
& \operatorname{EFE}\left(\mathrm{mJ} / \mathrm{m}^{2}\right)=16,7+2,1(\% \mathrm{Ni})-0,9(\% \mathrm{Cr})+0,26(\% \mathrm{C})
\end{aligned}
$$

Os valores da energia de falha de empilhamento e seus respectivos mecanismos dominantes de deformação estão descritos a seguir [15]:

- EFE $<18$ mJ/m²: Transformação martensítica;

- EFE 18 - 45 mJ/m²: Maclagem;

- $\quad$ EFE > 45 mJ/m²: Deslizamento de discordâncias.

O objetivo do trabalho proposto foi avaliar a capacidade das ligas $\mathrm{Fe}-\mathrm{Ni}-\mathrm{Cr}$ em formar martensita através das ciclagens térmicas propostas ou então maclar-se em função das suas características composicionais e evidencias microestruturais obtidas. Para isso, o material foi submetido a tratamentos térmicos em 2 diferentes temperaturas de encharque sendo elas 800 e $1100^{\circ} \mathrm{C}$, e dois meios de resfriamento tais como salmoura e nitrogênio líquido foram utilizados. Para avaliação das modificações estruturais, foram utilizados ensaio tais como Microscopia Eletrônica de Varredura (MEV) associada a Espectroscopia de Energia Dispersiva de Raio-X (EDS) e Difração de Raio-X (DRX).

\section{MATERIAL E MÉTODOS}

O material estudado neste trabalho foi obtido na forma de barra cilíndrica de $40 \mathrm{~mm}$ de diâmetro. A liga em estudo se trata de um aço inoxidável austenítico da série 300 onde a composição química global estimada por EDS/MEV é apresentada na Tabela 1.

Tabela 1. Composição química da liga de estudo.

\begin{tabular}{cccccc}
\hline Elemento & $\mathbf{C}$ & $\mathbf{S i}$ & $\mathbf{C r}$ & $\mathbf{F e}$ & $\mathbf{N i}$ \\
\hline Fração Mássica (\%) & 1,31 & 0,27 & 27,35 & 50,66 & 20,41 \\
\hline
\end{tabular}

A barra foi cortada em discos de aproximadamente 2 a $3 \mathrm{~mm}$ de espessura e posteriormente 1 dos discos foi dividido em fatias de 1/8 aproximadamente. Após o corte uma das amostras foi retirada para que se pudesse caracterizá-la no estado de como recebido e quatro seguiram para as etapas de tratamento térmico, onde as 
amostras foram inseridas aos pares em um forno tipo mufla pré-aquecido na temperatura de encharque onde permaneceram por uma hora. Em seguida estas foram submetidas a resfriamentos em meios diferentes. Foram adotadas 2 temperaturas de encharque: 800 e $1100^{\circ} \mathrm{C}$, de modo a avaliar o efeito no crescimento de grão da matriz e dissolução da segunda fase presente na condição como recebida. Os meios de resfriamento adotados foram: (i) solução de salmoura com gelo, álcool etílico e cloreto de sódio, resultando em uma temperatura de aproximadamente $-10^{\circ} \mathrm{C}$; e (ii) nitrogênio líquido (aproximadamente $-196^{\circ} \mathrm{C}$ ), com base em trabalhos prévios, após 5 minutos de imersão estabilização da temperatura a amostra a $-115^{\circ} \mathrm{C}$.

Com o intuito de realizar análise metalográfica e difração de raio- $\mathrm{X}$, as superfície das amostras foram preparadas seguindo procedimento comum. Estas foram embutidas à frio em resina acrílica a fim de se evitar modificações estruturais provenientes do aquecimento do embutimento a quente (temperatura aproxima a $180^{\circ} \mathrm{C}$ ). Os corpos de prova foram submetidos a lixamento com diminuição gradativa do tamanho de abrasivo da lixa até a granulometria de 4000 mesh em lixadeira rotativa manual seguida de polimento eletrolítico com solução de $20 \%$ de ácido perclórico em álcool etílico por 30 segundos com $20 \mathrm{~V}$.

O aspecto microestrutural e modificações resultantes dos tratamentos térmicos adotados foram analisados por Microscopia Eletrônica de Varredura em um microscópio FEI modelo Quanta FEG 250. Inicialmente realizou-se na amostra como recebida testes de tensão, distancia de trabalho (WD) e spot size a fim de determinar a melhor condição de análise entre os detectores de elétrons secundários (ETD) e elétrons retroespalhados (BSED). A melhor condição foi obtida pelo detector de BSED com tensão de aceleração de $20 \mathrm{KV}$, WD de aproximadamente $8 \mathrm{~mm}$ e spot size de 5 . Também foram realizadas avaliações pontuais por Espectroscopia de Energia Dispersiva de Raios-X (EDS) a fim de estimar se havia diferença composicional entre a matriz (parte clara) e a segunda fase (parte escura). Sendo este realizado nas condições de WD de aproximadamente $10 \mathrm{~mm}$, tensão de $20 \mathrm{KV}$ e spot size de 5 . Em ambas as análises foi utilizada a abertura de 5 .

As amostras foram submetidas à difração de raios $x$ em um difratômetro PANalytical, modelo MRD Pro, com anodo de Cobalto, acoplamento $\theta-2 \theta$ (ângulo de Bragg) no modo passo-a-passo, no intervalo angular de $20^{\circ}$ a $140^{\circ}$ de 2 Theta, com passo angular de $0,02^{\circ}, 100$ segundos por passo na faixa de trabalho de tensão e corrente de $40 \mathrm{kV}$ e $45 \mathrm{~mA}$, respectivamente.

\section{RESULTADOS E DISCUSSÃO}

A temperatura teórica de início da transformação martensítica foi calculada utilizando-se as equações 1e 2 como base.

Ao resolver as equações com os valores percentuais de elementos de liga presentes na amostra (informações da tabela 1), obteve-se valores das temperaturas Ms para as equações 1 e 2 de $-5878,7^{\circ} \mathrm{C}$ e $-3231,28^{\circ} \mathrm{C}$, respectivamente. Ao observar os valores de Ms, pode-se concluir que essa transformação é termodinamicamente impossível, sugerindo que a liga não é passível de transformação martensítica por ciclagem térmica.

Em seguida, realizou-se os cálculos para obtenção do valor da energia de falha de empilhamento utilizando as equações 3 e 4 . Como resultados obteve-se os valores 
de $-160,397 \mathrm{~mJ} / \mathrm{m}^{2}$ para a equação 3 e $35,2506 \mathrm{~mJ} / \mathrm{m}^{2}$ para a equação 4 . Em relação a energia de falha de empilhamento pode-se observar que de acordo com a equação 3 é possível que o material sofra transformação martensítica por ciclagem térmica, já pela equação 4, indica a formação de maclas no material.

Os valores obtidos pelas quatro equações foram estimados com base em informações composicionais obtidas pela técnica de EDS, que é uma análise semiquantitativa que apresenta limitações em revelar elementos de baixo percentual e residuais. Sendo assim como é uma estimativa, os valores obtidos pelas equações de Ms e EFE são apenas indicativos e de pouco confiabilidade principalmente pelo teor de carbono computado (fora do habitual para estes aços $[5,7,8]$ ). Espera-se com a continuidade desse trabalho realizar análises de fluorescência de raio $X$ (FRX) para garantir maior precisão nos resultados das equações. Com valores mais confiáveis e com teores de carbono em percentuais habituais, mesmo que os valores sejam termodinamicamente impossíveis, os valores se farão mais próximos do zero absoluto para Ms.

Como a temperatura teórica Ms dada pelas equações 1 e 2 são impossíveis, as amostras tratadas foram observadas por MEV na procura de indícios da transformação. Na figura 1 é mostrada a imagem da microestrutura da amostra como recebida, enquanto na figura 2 são mostradas as microestruturas das amostras submetidas aos tratamentos térmicos a 800 e $1100^{\circ} \mathrm{C}$ e resfriadas em salmoura. Por fim, na figura 3 são mostradas as microestruturas das amostras tratadas as mesmas temperaturas, porém resfriadas em nitrogênio líquido.
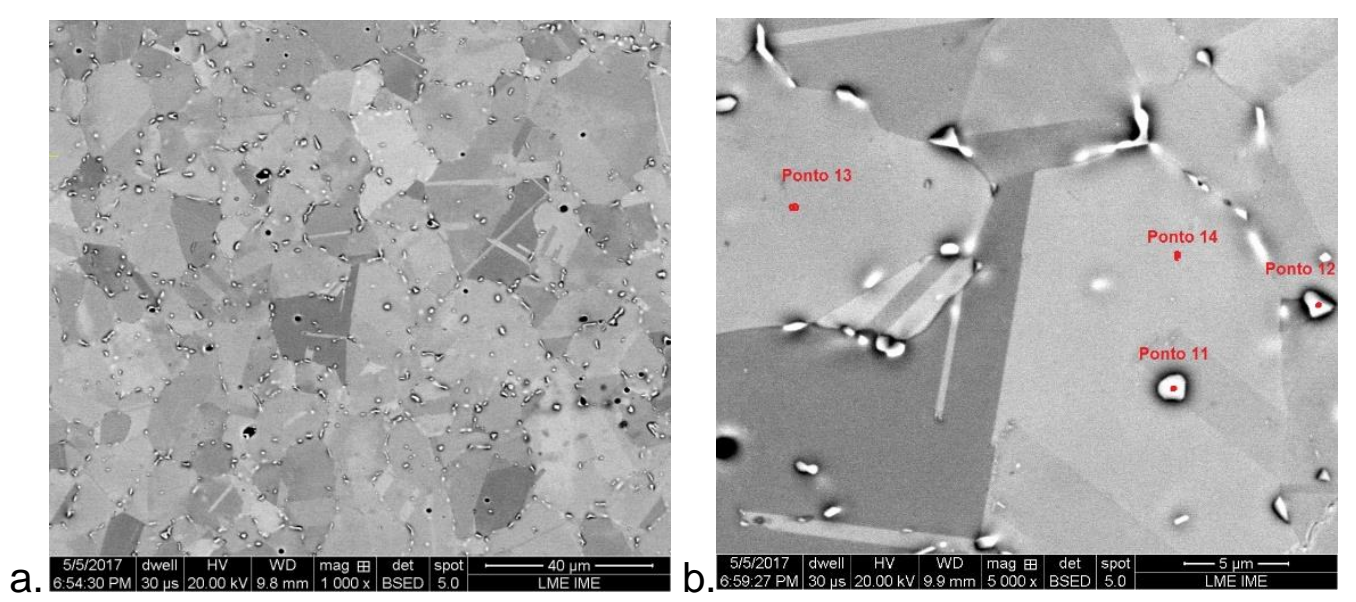

Figura 1. Microestrutura da amostra como recebida - aumentos de 1000x e 5000x, com pontos associada as análises de EDS em (b).

Tabela 2. Composições dos pontos, em \%peso, destacadas na Figura $1 \mathrm{~b}$ da amostra como recebida.

\section{Pontos analisados}

\begin{tabular}{ccccc}
\hline Pontos / & \multicolumn{2}{c}{ Segunda Fase } & \multicolumn{2}{c}{ Matriz } \\
\cline { 2 - 5 } Elementos & $\mathbf{1 1}$ & $\mathbf{1 2}$ & $\mathbf{1 3}$ & $\mathbf{1 4}$ \\
\hline $\mathbf{C}$ & 2,55 & 2,27 & 0,25 & 1,07 \\
\hline Si & 0,3 & 0,03 & 0,03 & 0,65 \\
\hline $\mathbf{C r}$ & 59,27 & 37,7 & 26,47 & 26,47 \\
\hline $\mathbf{F e}$ & 29,2 & 42,05 & 51,4 & 51,17 \\
\hline $\mathbf{N i}$ & 8,06 & 17,69 & 21,84 & 20,65 \\
\hline Mo & 0,63 & 0,25 & - & - \\
\hline
\end{tabular}

No que diz respeito ao aspecto microestrutural da condição como recebida (figura 1) são observados grão equiaxiais vinculados a matriz metálica, com algumas maclas 
no seu interior, e uma segunda fase, principalmente presente na região de contorno de grão da matriz. Em relação a análise de EDS em pontos da matriz e da segunda fase (figura $1 \mathrm{~b}$ e tabela 2), observa-se um maior percentual de $\mathrm{Cr}$ e menor de $\mathrm{Fe} \mathrm{e}$ $\mathrm{Ni}$ na segunda fase do que que na matriz metálica. Como também evidencias de teores baixos de Molibdênio na segunda fase.

$\mathrm{O}$ aumento selecionado para as imagens das Figuras de 1 a 3, foi de 1000x, de modo a comparar a amostra como recebida com as demais revelando o efeito principal das temperaturas de encharque no tamanho de grão da matriz. Onde o tratamento a $800^{\circ} \mathrm{C}$ basicamente resultou no mesmo tamanho de grão (inferior a $25 \mu \mathrm{m}$ ), enquanto que a $1100^{\circ} \mathrm{C}$ ocorreu um aumento muito significativo do mesmo (próximo a $100 \mu \mathrm{m}$ ). Outro aspecto distinto entre as amostras tratadas com temperaturas de 800 e $1100^{\circ} \mathrm{C}$ é que nos contornos de grãos da fase da matriz observa-se uma tênue coloração mais claro, que pode ser deveria a difusão de soluto entre a segunda fase e a matriz que resulta numa estreita linha de segregação nesta região. Este aspecto deve ser a justificativa para a retenção do crescimento de grão nesta temperatura, atribuída a presença de precipitados na região de contorno de grão da austenita (nas condições como recebida e tratadas a $800^{\circ} \mathrm{C}$ ).
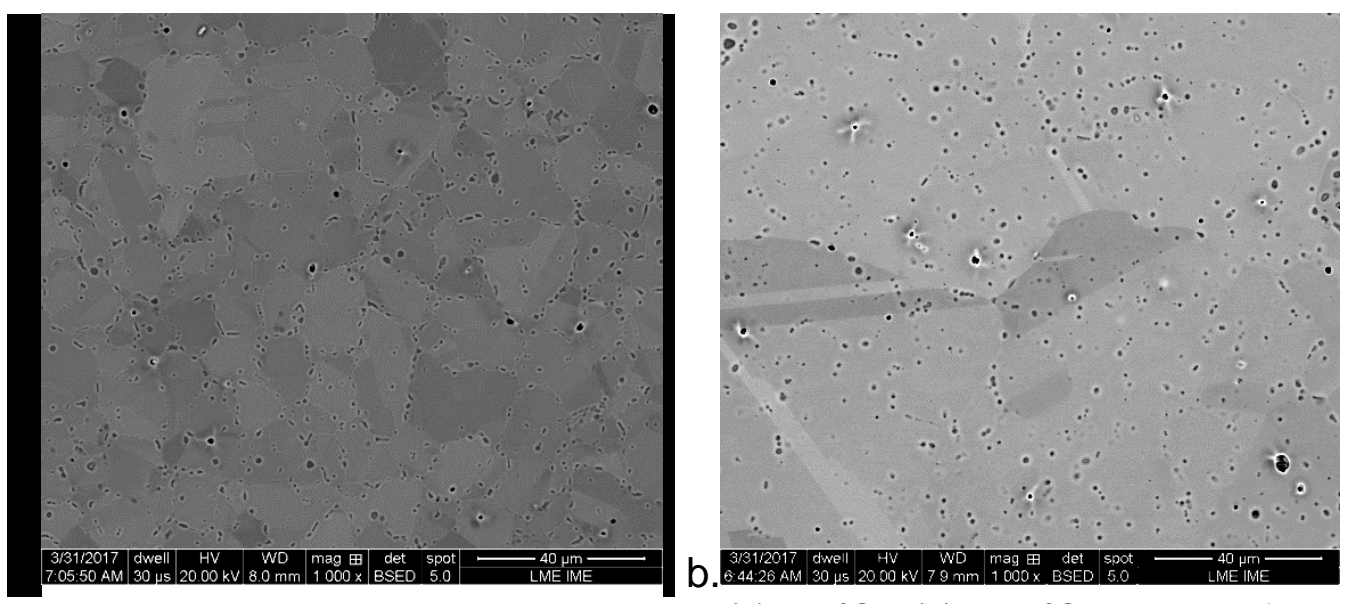

Figura 2. Microestrutura das amostras aquecidas a (a) $800^{\circ} \mathrm{C}$ e (b) $1100^{\circ} \mathrm{C}$, ambas resfriadas em salmoura - aumento de 1000x.
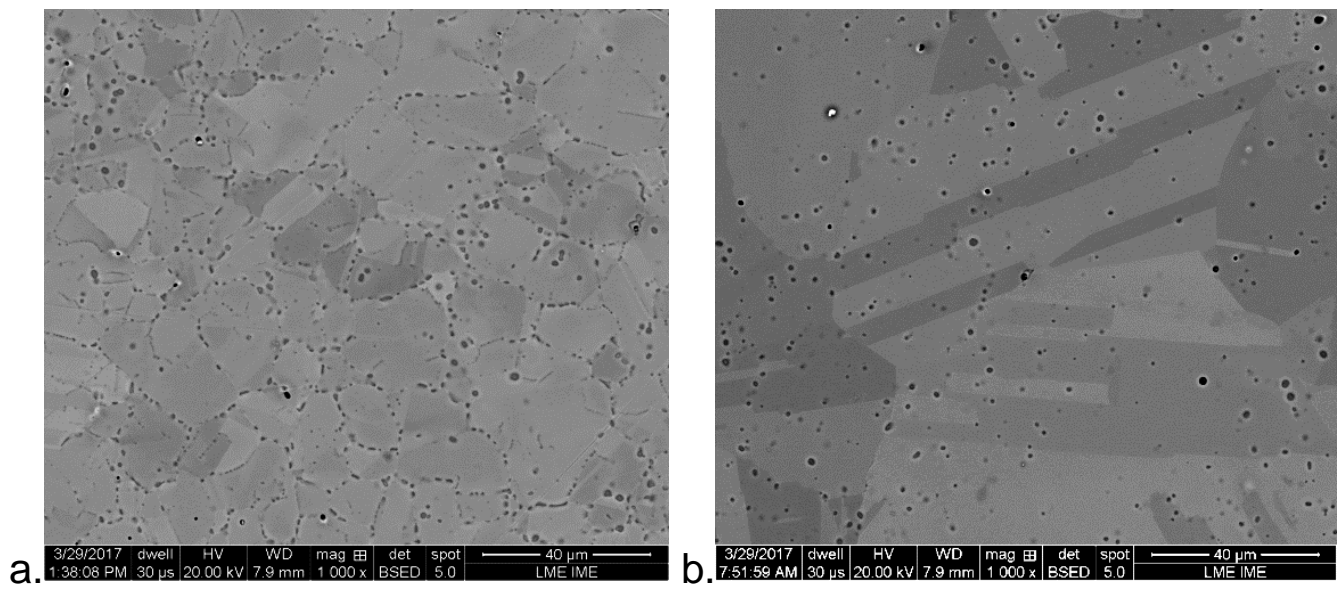

Figura 3. Microestrutura das amostras aquecidas a (a) $800^{\circ} \mathrm{C}$ e (b) $1100^{\circ} \mathrm{C}$, ambas resfriadas em Nitrogênio - aumento de 1000x. 
Através das figuras 4 e 5 pode-se visualizar mais detalhadamente os efeitos da ciclagem térmica na microestrutura, por intermédio de micrografias com aumento de 5000x, em comparação a amostra como recebida (Figura 1b).

Como pode ser observado nas microestruturas apresentadas nas figuras de 1 a 5 , a ciclagem térmica promoveu uma alteração na microestrutura do material. Entretanto, baseado na informação do valor de Ms calculado e nas imagens apresentadas, aparentemente não houve a formação de martensita em nenhum dos tratamentos observados.

$\mathrm{O}$ aspecto das microestruturas resultantes dos tratamentos térmicos (Figuras de 2 a 5) revela o surgimento de um maior número de maclas, do que o apresentado na condição como recebida (Figura 1). Estas maclas seriam de deformação devido as tensões geradas durante o resfriamento abrupto, seja em salmoura ou nitrogênio líquido, neste último mais intenso. Na temperatura de encharque de $1100^{\circ} \mathrm{C}$ para 0 resfriamento feito, tanto em salmoura quanto em nitrogênio, a presença destas estruturas se faz bem mais evidente do que as amostras de temperatura de encharque de $800^{\circ} \mathrm{C}$. Isso pode ser justificado pela maior severidade do tratamento, em função da maior diferença de temperatura da amostra e dos meios de resfriamento, que irá inserir maiores tensões e, consequentemente, deformação no material.
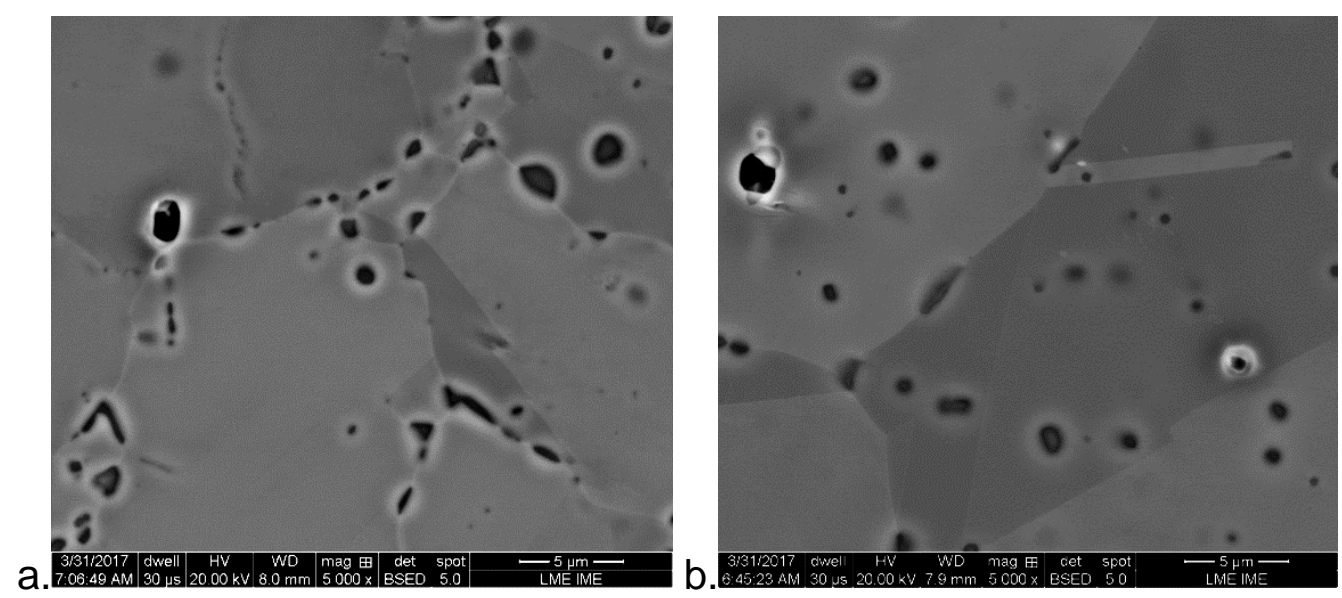

Figura 4. Microestrutura das amostras aquecidas a (a) $800^{\circ} \mathrm{C}$ e (b) $1100^{\circ} \mathrm{C}$, ambas resfriadas em salmoura - aumento de 5000x.
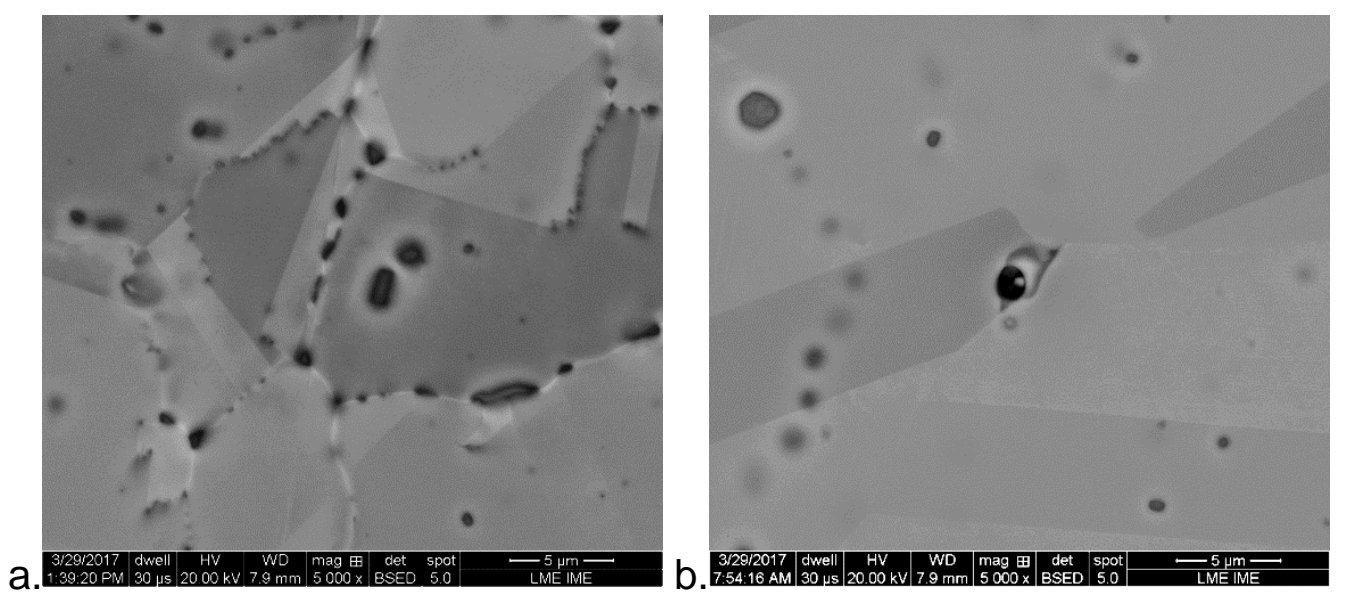

Figura 5. Microestrutura das amostras aquecidas a (a) $800^{\circ} \mathrm{C}$ e (b) $1100^{\circ} \mathrm{C}$, ambas resfriadas em Nitrogênio - aumento de 5000x. 
Neste tipo de liga é comum o aparecimento da fase ferrita delta (como segunda fase), devido à grande quantidade de solutos estabilizadores desta fase juntamente com a austenita.

Assim, ao comparar-se as figuras de 1 a 5 pode ser observado que há uma diminuição da fase mais escura em relação ao aumento do tamanho de grão da fase mais clara, quando compara-se as diferentes temperaturas de encharque para um mesmo meio de resfriamento. É observado que na temperatura de encharque de $1100^{\circ} \mathrm{C}$ a fase escura se tornou aparentemente residual. Devido à maior temperatura, que facilita os processos difusivos durante o tempo em que o material se manteve aquecido na temperatura de encharque, os elementos de liga presentes na segunda fase tenderão a migrar para a matriz.

$\mathrm{Na}$ figura 6 encontra-se a imagem de uma das micrografias das amostras $\left(1100^{\circ} \mathrm{C} /\right.$ Nitrogênio) tomadas como exemplo, a fim de elucidar as variações composicionais entre a matriz (fase clara) e a segunda fase (fase escura), onde estão presentes pontos com distintos percentuais de $\mathrm{Cr}$, $\mathrm{Ni}$ e $\mathrm{Fe}$ e outros elementos residuais. $\mathrm{Na}$ tabela 3 estão apresentados exemplos de composição em \%peso dos pontos.

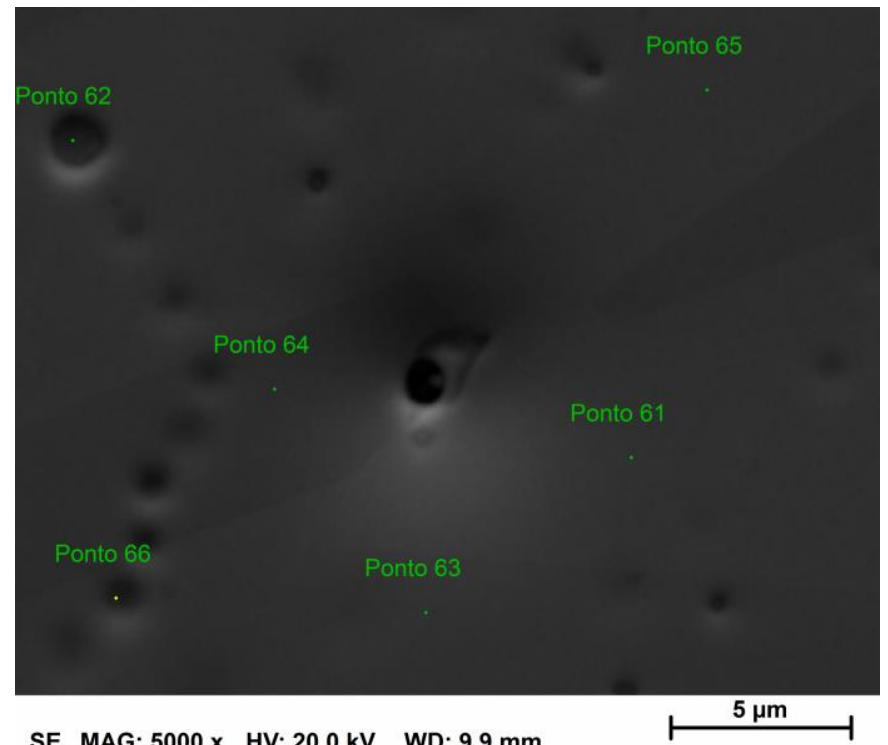

Figura 6. Definição de pontos para análise de EDS entre a matriz e segunda fase.

Tabela 3. Composições dos pontos, em \%peso, destacadas na Figura 6.

\section{Pontos analisados}

\begin{tabular}{ccccccc}
\hline Regiões/ & \multicolumn{3}{c}{ Matriz } & & Macla & \multicolumn{2}{c}{ Segunda fase } \\
\cline { 2 - 7 } Elementos & $\mathbf{6 1}$ & $\mathbf{6 3}$ & $\mathbf{6 5}$ & $\mathbf{6 4}$ & $\mathbf{6 2}$ & $\mathbf{6 6}$ \\
\hline $\mathrm{C}$ & 1,43 & 1,64 & 1,65 & 1,18 & 1,62 & 1,47 \\
\hline $\mathrm{Si}$ & 0,53 & 0,57 & 0,57 & 0,08 & 0,43 & 0,44 \\
\hline $\mathrm{Cr}$ & 27,08 & 27,01 & 25,92 & 26,07 & 41,28 & 24,82 \\
\hline $\mathrm{Fe}$ & 50,83 & 50,62 & 50,70 & 50,64 & 40,57 & 50,13 \\
\hline $\mathrm{Ni}$ & 19,95 & 19,94 & 20,96 & 21,95 & 15,10 & 22,93 \\
\hline $\mathrm{Mo}$ & - & - & - & - & - & - \\
\hline
\end{tabular}

Através da avaliação da figura 6 e tabela 2 pode-se destacar que não há diferença composicional entre a região maclada e não maclada da matriz. Esse fato pode ser visualizado analisando a composição dos pontos 61 e 64 . Em relação a matriz e a segunda fase é possível notar diferenças que podem ser visualizadas na diferença 
de composição dos pontos 61/62/65 e 63, por exemplo. Outra comparação a se fazer é com a análise de EDS realizada na amostra como recebida (Figura 1b e tabela 2) em relação a de uma das amostras tratadas (Figura 6 e tabela 3):

- deixa-se de detectar-se o elemento Mo na segunda fase após o tratamento térmico;

- as diferenças dos teores de $\mathrm{Cr}$, Fe e $\mathrm{Ni}$ entre a matriz e a segunda fase tornam-se menores;

- do ponto de vista de aspecto microestrutura em função do resultado do polimento eletrolítico, a segunda fase passa a apresentar-se em baixo relevo após 0 tratamento térmico.

Na figura 7 são mostrados os picos de difração de raios $x$ obtidos para as amostras em estudo, onde se observa a fase cfc da matriz (austenita - $\gamma$ ) com os mesmos picos de difração para todas as condições analisadas. No entanto, para as amostras resfriadas em nitrogênio líquido para ambas as temperaturas de encharque (Figura $7 \mathrm{~d}, \mathrm{e})$, evidencia uma redução na intensidade dos picos de difração da austenita, e por outro lado para amostras tratadas a $800^{\circ} \mathrm{C}$, verifica-se a detecção de 2 novos picos (primeiro não identificada e o segundo coincide com o pico (211) da estrutura (cc). A variação de intensidade dos picos de difração da austenita poderia ser justificado pela maior ocorrência de maclas como resultado do resfriamento com nitrogênio líquido, influenciado assim na textura do material. Enquanto o surgimento de 2 novos picos de difração este pode ser justificado pela aparente segregação de soluto na região de contornos de grãos que na condição como recebida continha uma quantidade expressiva de segunda fase e reduzida por este tratamento. 




Figura 7. Difratogramas sobrepostos para as amostras como recebida (a) aquecidas à $800^{\circ} \mathrm{C} e$ resfriadas em salmoura e nitrogênio (S800 (b) e N800 (d), respectivamente) e aquecidas à $1100^{\circ} \mathrm{C}$ e resfriadas em salmoura e nitrogênio (S1100 (c) e N1100 (e), respectivamente).

Como base no exposto, analises complementares e aprofundadas estão sem conduzidas de modo a entender melhor o que ocorre nestas temperaturas de encharque neste material. A citar:

- análise de FRX para análise química global e de EDS para mapeamento composicional microestrutural, a fim de avaliar por esta última à variação composicional da segunda fase e matriz, e confirmar a presença de segregação na região de contorno de grão das amostras tratadas a $800^{\circ} \mathrm{C}$.

- análise de difração de elétrons retroespalhados (EBSD) / MEV a fim de quantificar maclas, melhor definir a estrutura da segunda fase, aparentemente associada a picos duplos da austenita na análise de DRX apresentada, e averiguar quanto à possibilidade da presença de uma ou mais fases no material resultante do resfriamento com nitrogênio líquido.

- análise de DRX em temperatura a fim de avaliar a evolução estrutural do material em altas temperaturas em confronto com análise dilatometria.

- medidas de ultramicrodureza instrumentada Vickers, a temperatura ambiente, com distintas cargas de modo a verificar se as variações composicionais nas estruturas das fases da matriz e segunda fase são significativas na variação na variação da dureza macro do material sob estas condições em estudo. 
- por fim medidas de textura via DRX de modo a constatar se a maior ocorrência de maclas influenciou na textura resultante das amostras resfriadas com nitrogênio liquido.

\section{CONCLUSÕES}

Em função dos resultados apresentados e da discussão realizada para a liga em estudo, conclui-se que:

- Com base nos cálculos de Ms através de equações empíricas vinculado a composição química estimada e observações estruturais não se faz presente a transformação martensítica induzida por ciclagem térmica no material. No entanto, para as condições de tratamento térmico com temperatura de encharque $800^{\circ} \mathrm{C}$, fez presentes evidencias de outras fases (uma delas identificada como ccc) justificado por uma variação local de composição na matriz junto aos seus contornos de grão.

- As condições de encharque adotadas modificaram de maneira significativa a microestrutura do material, em termos de crescimento do tamanho de grão da matriz e redução da fração de segunda fase com aumento da temperatura de encharque.

- Os meios de resfriamento criogênicos adotados são impactantes na microestrutura do material solubilizado em alta temperatura durante seu resfriamento, pela formação de maclas características do processo de deformação possivelmente provenientes das tensões geradas pelo aumento da severidade de resfriamento em função da diferença de temperatura de encharque e do meio de resfriamento.

\section{Agradecimentos}

Os autores agradecem aos professores TC José Ricardo Gomes Matheus e Carlos Sérgio da Costa Viana pela doação de material para este estudo, ao IME pelos recursos disponibilizados para realização deste trabalho, e em particular ao aluno de doutorado Eustáquio Baeta pela realização das medidas de difração de Raios-X. L.F. Nunes e N.T. Simonassi agradecem as bolsas de mestrado e doutorado da agência CAPES. A.S. Paula agradece a bolsa de produtividade à pesquisa (PQ-2) do CNPq (Processo 307798/2015-1).

\section{REFERÊNCIAS}

1 CHIAVERINI, V. Aços e ferros fundidos. 7ª ed. São Paulo: ABM, 2008.

2 BUBANI, F. DE C., DECARLI, C. C. M., BROLLO, G. L., BARRETO, E. H., DINIZ, A. E., PAULO, R.M. Efeito da temperatura na estrutura e na estabilidade de ligas $\mathrm{Fe}-18 \mathrm{Cr}$ (0 a 60) Ni. R. Esc. Minas. 2010; v. 63(1): 045-050.

3 GONTIJO, L.C., MACHADO, R., CASTELETTI, L.C., KURI, S.E., NASCENTE, P.A.P. Comparação Entre Os Comportamentos Dos Aços Inoxidáveis AISI 304L e AISI 316L Nitretados A Plasma. Revista Brasileira de Aplicações de Vácuo. 2007; v. 26(3): 145150. 
4 PINTO, T.B. Estudo das transformações de fases e dos mecanismos de deformação de aços inoxidáveis do tipo AISI 304. Belo Horizonte: CETEC. 2002. 22p. (Relatório Técnico).

5 DAVIS, J. R. ASM Specialty Handbook: Stainless Steels. Materials Park. Ohio: ASM International, 1996.

6 SINHA, A. K. Physical Metallurgy Handbook, MacGraw Hill ed., 2003. p.10.50.

7 APERAM. Aços inoxidáveis austeníticos para altas temperaturas. Fichas técnicas.indd. 2012.

8 VILLARES METALS. Aço inoxidável austeníticos. Fichas técnicas. 2009.

9 Krupp U, West C, Christ HJ. Deformation-induced martensite formation during cyclic deformation of metastable austenitic steel: Influence of temperature and carbon content. Mater Sci Eng A 2008.

10 GUY, K. et al. $\varepsilon$ and ' $\alpha^{\prime}$ martensite formation and reversion in austenitic stainless steels. Journal de Physique, v.43, p. 575, 1982.

11 PICKERING, F. B. Physical metallurgical developmentes of stainless steels. Proc. Conf. Stainlees steel, 84, Gothenburg, 1984.

12 TALONEN, J.; ASPEGREN, P.; HÄNNINEN, H. Comparison of different methods for measuring strain induced $\alpha^{\prime}$-martensite content in austenitic steels. Materials Science and Technology, Vol. 20, pp.1506-1511, 2004.

13 HEDAYATI A.; NAJAFIZADEH, A.; KERMANPUR, A.; FOROUZAN, F.. The effect of cold rolling regime on microstructure and mechanical properties of AISI $304 \mathrm{~L}$ stainless steel, Journal of Materials Processing Technology, Vol. 210, pp. 1017-1022, 2010

14 BEHJATI P., KERMANPUR A. e NAJAFIZADEH A. Application of Martensitic Transformation Fundamentals to Select Appropriate Alloys for Grain Refining Through Martensite Thermomechanical Treatment, Metallurgical and Materials Transactions A.: The Minerals, Metals \& Materials Society and ASM International, Vol. 44A, pp. 3524353, 2013.

15 SHEN Y.F., LI, X.X.; SUN, X.; WANG, Y.D.; ZUO, L.; Twinning and martensite in a 304 austenitic stainless steel, Materials Science and Engineering, Vol. 555, pp. 514522, 2012. 